\title{
Dyspnea and the cancer
} patient

\section{- An overview}

\section{By Alma Acheson and Donna MacCormack}

\section{Abstract}

Dyspnea, a distressing subjective symptom common in patients with advanced cancer, has been vastly under-reported. It can be directly caused from the tumour such as in superior vena cava obstruction: indirectly caused from debilitating conditions such as pneumonia or pulmonary embolism; or related to treatment such as surgery or radiation therapy. Nursing assessment and diagnosis are discussed. The authors present strategies for the management of dyspnea that nurses will find helpful when confronted with this symptom. Nurses play an important role in helping patients and their families to cope with dyspnea and to maintain as normal a lifestyle as possible.

\section{Introduction}

Dyspnea is an uncomfortable awareness of breathing that can seriously affect quality of life for cancer patients. The word itself comes from the Greek roots of $d y s$ for hard or disorganized and pnoia for breathing.

It is a subjective symptom characterized by difficult laboured breathing. The objective signs often do not match the patient's perception of the problem or the limitations to his/her activity.

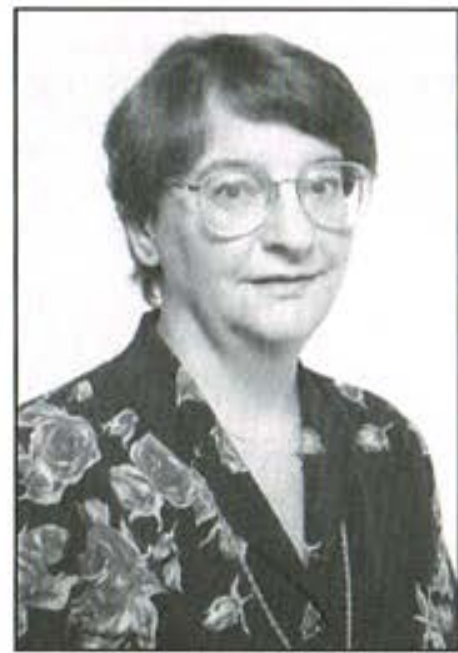

Alma Acheson

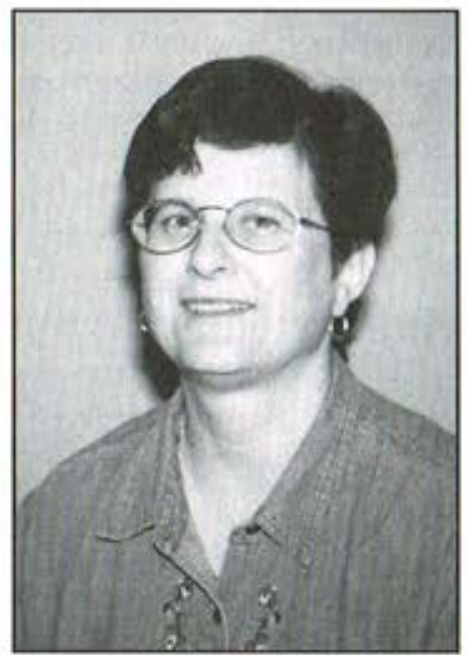

Donna MacCormack
Patients will often use terms like "shortness of breath", "hard to move air". "tightness", "filling up", and "drowning" to describe the physical sensation (Brown, Carrieri, Janson-Bjerklie, Dodd, 1986, p.21). Next to nausea/vomiting and pain, it is the symptom most troubling for patients. It may be acute, but in cancer patients is usually chronic.

Despite its frequency, little research has been done on dyspnea. While there are many articles on the subject, there are few new ideas for management of the problem in the literature.

\section{Epidemiology}

The frequency and severity of dyspnea has been vastly underreported. The National Hospice Study was conducted in 40 hospices and 14 conventional care settings in the United States. Rueben and Mor in 1986 found that $70.2 \%$ of patients in this study reported dyspnea in the last six weeks of life. The degree of dyspnea was at least moderate in $28 \%$ of these patients (Rueben, Mor, 1986). Muers and Round found $60 \%$ of their study group of patients with non small cell lung cancer had shortness of breath as a complaint on presentation. At that time, $50 \%$ of this group reported the problem as moderate to severe and, prior to death $90 \%$ of this group complained of dyspnea (Dudgeon, Rosenthal, 1996). In a study by Dr. D. Dudgeon et al. conducted in outpatient settings of the Manitoba Cancer Treatment and Research Foundation, $49.1 \%$ of a random 1,000 outpatients given a questionnaire using a verbal rating scale reported dyspnea, with $20.1 \%$ of these reporting moderate to severe symptoms (ASCO Abstract \#321).

Of particular note is a study by Roberts, Thorne and Pearson in which it was found that while $76.7 \%$ of patients in hospital claimed on interview to experience dyspnea, only $38.8 \%$ of these cases were reported by nursing staff (Roberts, Thorne, Pearson, 1993). The questions that remain to be answered are: do patients feel that breathlessness is part of the disease process about which nothing can be done and which must be tolerated; have they received the message that dyspnea is not important; or are nurses not assessing the presence of this symptom and observing signs that might indicate its presence?

\section{Causes}

Causes of dyspnea can be grouped into four categories: direct, indirect, treatment-related and other related conditions (Dudgeon, Rosenthal, 1996).

\section{ABRÉGÉ}

\section{UN APERÇU DE LA DYSPNÉE CHEZ LES PATIENTS ATTEINTS DE CANCER}

La dyspnée, un symptôme subjectif pénible souvent présent chez. les patients souffrant de cancers à un stade avancé, est en grande partie sous-déclarée. Elle peut être causée directement par la tumeur comme dans les cas d'obstruction de la veine cave supérieure, ou bien être causée indirectement par des conditions débilitantes telles que la pneumonic ou l'embolie pulmonaire; ou encore trouver son origine dans les traitements tels que la chirurgie ou la radiothérapie. L'article examine l'évaluation et le diagnostic infirmiers. Les auteures y présentent des stratégies de gestion de la dyspnée qui seront utiles aux infirmières lorsqu'elles se trouvent en présence de ce symptôme. Les infirmières jouent un rôle essentiel en aidant les patients et les familles à s'adapter à la dyspnée et à continuer de mener une vie aussi normale que possible.

\begin{abstract}
Alma Acheson, RN, BA, is nursing coordinator, Manitoba Cancer Care Network, Manitoba Cancer Treatment and Research Foundation, and Donna MacCormack, RN, BScN, is research nurse, clinical investigations office, Manitoba Cancer Treatment and Research Foundation, Winnipeg, Manitoba.
\end{abstract}


Direct causes are those resulting from tumour effects. This would include bronchial obstruction, superior vena cava obstruction, tumour invasion of the lung tissue, lymphangitic spread, phrenic nerve paralysis, pleural effusions, pericardial effusion, ascites and/or hepatomegaly.

Indirect causes include those conditions which can precipitate or contribute to dyspnea but result as an effect of the disease. These are often classified as debilitating conditions and include anemia, cachexia, pulmonary embolism, pulmonary aspiration, pneumonia, electrolyte imbalances, mucositis and infection.

Treatment-related causes include surgery (pneumonectomy), radiation therapy (fibrosis or pneumonitis) and chemotherapyinduced problems, e.g. cardiomyopathy, pulmonary disease.

There are also factors unrelated to cancer which may precipitate dyspneic episodes. These could include emotional factors such as anxiety or fear; physical activities such as walking up stairs; mechanical behaviours such as crying, laughing or smoking; environmental conditions such as pollens, smoke in rooms, wind and bad weather (Brown, Carrieri, Janson-Bjerklie, Dodd, 1986). Other factors could include routine nursing measures, e.g. changing positions, manipulating IVs, blood sample collection and suctioning. Underlying medical conditions such as chronic obstructive pulmonary disease and congestive heart failure, asthma, obesity, hereditary or acquired medical conditions, will also affect dyspnea.

The most common groups of cancer to cause dyspnea are lung, colorectal and breast. Nearly two-thirds of all dyspneic patients who participated in the National Hospice Study suffered from one of these underlying malignancies (Rueben, Mor, 1986). The presence of lung or pleural involvement in cancer patients is one of the best predictors of dyspnea.

It is important to identify the cause of the dyspnea. If treatable, then appropriate measures should be taken. If the underlying cause is unidentifiable or untreatable, then palliative measures should be used.

\section{Assessment and diagnosis}

Dyspneic events follow a common pattern. This pattern usually consists of a precipitating factor, a slow onset, a plateau and then a gradual improvement once intervention strategies are instituted.

As previously stated, dyspnea is a subjective sensation and does not necessarily match the patient's functional level. Patients reporting dyspnea also report other physical sensations such as "poor concentration, loss of appetite, loss of memory, smothering and sweating. Patients also described emotions felt during the dyspneic episodes including anger, helplessness, depression, loss of strength, agitation, anxiety, nervousness and fear" (Brown et al., 1986, p. 21).

Existing measurement tools that can be used are such things as time walking, walking oximetry, stair walking. physiologic tests such as pulmonary function tests including spirometry, blood gases and oxygen saturation levels. These are all objective tools. Subjective measurement tools are the VAS (visual analogue scale), VRS (verbal rating scale), the GRS (graphic rating scale), and the Borg scale. In these tests, the patient rates the level of dyspnea as he/she perceives it, thereby giving the caregiver more insight into the patient's state at any given time.

Other information that must be gathered in order to properly assess the dyspnea and help to determine the intervention is a complete history of the onset, the precipitating events, responses to medications and interventions previously used, and a past history of conditions or factors which may influence the breathlessness, e.g. smoking, cardiac problems, other medical conditions, and previous therapies. The emotional status at onset and as the symptom progresses is also very important to determine if there is a relationship between such emotions as anxiety, agitation and fear; and the perceived difficulty breathing. A careful physical examination, blood tests and chest $x$-rays are appropriate to determine if there are other factors contributing to the problem.

During the examination and after the intervention, the patient should be observed for distress, restlessness and perspiration. The respiratory rate and method of breathing (indrawing, abdominal respirations) should be observed. As well, the presence of fever. cough and an assessment of chest sounds will help determine the cause of the dyspnea. These observations are indicators as to the severity of the symptom. They are critical as the patient may not be able to communicate during a severe dyspneic attack.

It is important to attempt to differentiate between weakness and dyspnea as there is a close relationship between the two, with fatigue and weakness often being part of the debility of the disease and causing the dyspnea. In the second phase of her study of dyspnea in the advanced cancer patient, Dudgeon et al found that this patient population frequently has very low maximum inspiratory pressures. This suggests that respiratory muscle weakness may contribute to dyspnea in this patient population (Dudgeon, Lertzman, 1996).

It is also appropriate at this stage to assess the mental status and social supports that a patient has, as these will affect the interventions which can be handled by the patient and family.

The choice of tests and therapies should be guided by the stage of cancer, its prognosis, and the risk vs. benefit ratio.

\section{Nursing diagnosis}

The primary nursing diagnosis would be the inability to maintain efficient respiration.

Associated nursing diagnoses could include:

- impaired gas exchange

- ineffective breathing patterns

-activity intolerance

- disturbances in sleep pattern

- altered oral mucous membranes

- anxiety-related symptoms.

\section{Interventions}

A multidisciplinary team approach is necessary in the management of dyspnea. Nurses have a unique role because of their frequent contacts with patients and referrals to other agencies when appropriate (Grey, 1995). Each individual patient must be involved in planning the management of his or her dyspnea. Cowcher and Hanks (1990) have suggested a management plan that takes into account the patient's personal goals, as well as the stage and rate of progression of the disease. Treatment approaches can include pharmacologic therapy, oxygen therapy, physical and psychosocial techniques,

\section{Pharmacological approach}

The pharmacologic approach to managing dyspnea includes opioids, benzodiazepines and corticosteroids. In a study on the effects of morphine on dyspnea of terminal cancer patients, Bruera, Macmillan, Pither and MacDonald (1990) found that morphine can improve dyspnea without significantly altering respiratory rate, oxygen saturation or expiratory $\mathrm{CO}_{2}$ Morphine has the ability to reduce anxiety and change perception, which leads to lower oxygen requirements. Dudgeon and Rosenthal (1996) state that early use of morphine improves quality of life and allows lower doses to be used while developing tolerance to the respiratory depressant effects. Morphine and other opioids can be used in a nebulized form as well. Though the mechanism of action is not clearly understood, it is suggested that the nebulized forms have a peripheral effect on lung tissue producing relief of respiratory symptoms for up to four hours (Farncombe, Chater 1994). Diazepam or chlorpromazine, especially when used with relaxation therapy and breathing exercises, can be 
useful for reducing anxiety. Scopolamine can be used to manage copious amounts of secretions. Corticosteroids such as prednisone may be used to relieve bronchospasm, reduce tumour edema and reduce lymphangitis. Indomethacin, a non-steroidal antiinflammatory drug, is thought to be effective in reducing the perception of dyspnea. It acts in decreasing the production of prostaglandins which stimulate the $J$ receptors that are sensitive to edema.

\section{Oxygen therapy}

Bruera, Stoutz, Velasco-Leiva, Schoeller and Hanson (1993) have shown that oxygen decreases the intensity of dyspnea in hypoxic patients with terminal cancer. A double blind crossover trial was done to assess the effects of oxygen on the intensity of dyspnea. Fourteen patients with dyspnea due to advanced cancer were randomized to receive either oxygen or air, both given at five litres per minute by mask. After five minutes of stable oxygen saturation, patients were crossed over to receive the air treatment. The crossover was repeated twice. Twelve patients consistently chose oxygen over air as relieving dyspnea, and the investigators consistently concurred with the oxygen choice for the same 12 patients. Patients rated their dyspnea, respiratory rate and effort as significantly improved with oxygen as compared to air. Oxygen should be given at the lowest effective dose and a humidifier should be attached to the oxygen to prevent the respiratory tract from drying out. Directing a fan toward the patient or having him sit near an open window can reduce his perception of breathlessness and feeling of air hunger (Dudgeon et al., 1996).

\section{Breathing patterns}

Dyspnea may be managed by teaching patients new breathing patterns. The aims of breathing retraining (Bailey, 1995) are to promote a relaxed and gentle breathing pattern; to minimize the work of breathing; to establish a sense of control and to promote a sense of well-being. Breathing can be regulated by slow deep breaths using the diaphragm. Inhalation should be through the nose. Exhaling through pursed lips will help control the rate and depth of respiration. Patients are taught this technique by advising them to make a soft whistling sound when exhaling. Expiration should take twice as long as inhalation (Haylock, 1987). Ineffective breathing consumes more energy than necessary and shallow, gasping breaths

Table One: Summary of interventions

$\begin{array}{lc}\begin{array}{l}\text { Pharmacological } \\ \text { Opioids: }\end{array} & \text { Oxygen Therapy } \\ \text { Oral } & \text { Breathing Patterns } \\ \text { Parenteral } & \text { Diaphragmatic breathing } \\ \text { Nebulized } & \text { Pursed lip breathing } \\ \text { Benzodiazepines } & \text { Controlled breathing } \\ \text { Corticosteroids } & \text { Positioning } \\ \text { Anti-inflammatories } & \text { Sitting - slightly forward } \\ \text { Activities of Daily Living } & \text { position } \\ \text { Conservation of energy } & \text { Relaxation including: } \\ \text { Rest periods } & \text { Meditation } \\ \text { Support systems } & \text { Guided imagery } \\ \text { Anxiety Relief } & \text { Therapeutic touch } \\ \text { Do not leave alone } & \text { Relaxation tapes } \\ \text { Quiet environment } & \text { Radiotherapy } \\ \text { Support } & \text { Relieve obstruction } \\ \text { Reassurance } & \text { Reduce compression } \\ \text { Knowledge } & \end{array}$

contribute to anxiety and panic. The use of breathing techniques can decrease dyspnea and anxiety by giving patients confidence that some control can be maintained during an attack of breathlessness (Grey, 1995),

\section{Positioning}

Patients experiencing breathlessness will usually sit up automatically in order to breathe more easily. Proper positioning allows maximum relaxation of the upper chest and provides freedom of movement for the lower chest (Foote, Sexton and Pawlick, 1986). Several comfortable positions may be suggested. Sitting on the edge of the bed with arms folded on a pillow on the bedside table facilitates breathing and allows the person to relax. Sitting on a chair with feet wide apart and elbows resting on knees is another position. A third position is leaning on the wall with feet apart, shoulders relaxed and bent slightly forward. Elevating the head of the bed to 90 degrees also promotes maximum lung inflation (Foote et al., 1986).

Relaxation conserves oxygen and therefore relaxation exercises can be valuable since tense muscles use much of the limited oxygen supply and contribute to anxiety. One method involves placing hands on the patient's shoulders, then pressing downwards. Patients can be taught to dangle both arms and rotate the shoulders in circles, moving them forward, upward, back and down. Teaching family and friends allows them to do the exercises with the patient, thereby providing support and reassurance. Other approaches that promote relaxation include meditation, guided imagery, therapeutic touch and relaxation tapes. Relaxation methods are most effective when used after the patient has developed a sense of control through breathing methods (Haylock, 1986).

\section{Activities of daily living}

Nurses play a role in aiding patients with dyspnea to plan their activity. Planning activity allows the patient to conserve energy and to schedule periods of rest. Initially, normal lifestyle and activity must be assessed. Listing and defining activities as either light or heavy allows a patient to plan for pacing. A support system involving family and friends is needed in planning and doing both household and recreational activities. Offering nursing aids and social services when appropriate and acceptable will allow a patient greater independence. Nursing plays a crucial role in helping an ambulatory patient maintain as normal a lifestyle as possible (Foote et al, 1986).

\section{Relief of anxiety}

A distressing component of dyspnea is the high anxiety that accompanies it. It is important that patients in acute distress should never feel isolated. For hospitalized patients, the nurse needs to reassure the person that he/she is close by and quickly available when needed. This reduces the patient's anxiety and makes the experience of dyspnea easier to deal with (Gift, 1990). Patients in distress should not be left alone. Most prefer a quiet environment with people around them talking in slow, calm voices. For those living at home, setting up a phone line will assure them that someone is available to assist them in emergencies. Family members can offer support to the patient, especially if the nurse has taught them to coach the patient in relaxation and breathing methods. The patient's anxiety and dyspnea will be decreased by family support and reassurance. Nurses must provide emotional support to patients and their families. Patients should be informed that dyspnea is common in people with advanced cancer. The nurse can explain how the lungs work and how the patient's breathing is affected by his or her disease (Held, 1994). Patients with dyspnea should be encouraged to eat high caloric foods including liquid supplements. A nutritional diet is important to ensure the patient has energy to breathe. Patients should be encouraged to reduce 
environmental stimulants such as smoking and to physically distance themselves from irritant factors that cause them to experience dyspnea (Haylock, 1987).

\section{Radiotherapy}

Palliative radiotherapy may be used to relieve shortness of breath, although response is not normally rapid. It is used to relieve obstructed airway passages and reduce compression of blood and lymph vessels (Grey, 1995). Nurses play an important role in preparing the patient for radiotherapy treatment by informing the patient of what to expect prior to and during the treatment, the possible side effects, and interventions to manage these side effects.

In a study describing the patient's perception of dyspnea in lung cancer, Brown, Carrieri, Janson-Bjerklie and Dodd (1986) identified 70 strategies used by lung cancer patients. The average number of strategies used by an individual patient was 13.5 , with a range of 7 to 26. This average number was not affected by gender. This study categorized strategies as either short- or long-term. Changes in position and activity were the most frequent short-term strategies used for acute shortness of breath. Most of the strategies used were long-term adaptive strategies affecting lifestyle, activities of daily living or attitude. The emotional strategies used to cope with dyspnea included accepting the situation and trying to be positive. Over half of the patients preferred to be with family and friends rather than be alone. Eighty per cent, however, felt they had socially isolated themselves from friends and the community.

A recent study by Corner, Plant, Bailey and Krisanasamy (1995), reveals the effectiveness of nursing interventions taught in a nurseled clinic. Thirty-four patients with small cell or non small cell lung cancer who had completed first line therapy and were experiencing breathlessness were randomized to one of two groups: to attend a nursing clinic for their interventions or to be interviewed at their usual clinic visits and act as the control group. The results showed that the median score for breathlessness was significantly improved in the group attending the nurse-led clinic. The intervention group was able to increase their level of activity using breathing techniques taught at the clinic. Compared to the control group, these patients were better able to control episodes of panic, pace their activities and achieve a greater number of goals they had set for themselves.

\section{References}

Bailey, C. (1995). Nursing as therapy in the management of breathlessness in lung cancer. European Journal of Cancer Care, 4, 184-190.

Brown, M.L., Carrieri, V., Janson-Bjerklie, S., Dodd, M.J. (1986). Lung cancer and dyspnea: the patient's perception. Oncology Nursing Forum, 13(5), 19-24.

Bruera, E., de Stoutz, N., Velasco-Leiva, A., Schoeller, T., Hanson, J. (1993). Effects of oxygen on dyspnea in hypoxaemic terminal cancer patients. The Lancet, 342, 13-14.

Bruera, E., Macmillan, K., Pither, J., MacDonald, R.N. (1990). Effects of morphine on the dyspnea of terminal cancer patients. Journal of Pain and Symptom Management, 5(6), 341-344.

Corner, J., Plant, H., Bailey, C. (1995). Clearing the air. Nursing Times, 91(47), 42-43.

Cowcher, K., Hanks, G.W. (1990). Long term management of respiratory symptoms in advanced cancer. Journal of Pain and Symptom Management, 5(5), 320-330.

Dudgeon, D., Kristjanson, L, Khoo, K., Lertzman, M. (1996). Incidence of Dyspnea in Cancer Patients. Proceedings of ASCO(15), Abstract 321.

Dudgeon, D., Lertzman, M. (1996). Etiology of Dyspnea in Advanced Cancer Patients, Proceedings of ASCO, (15) Abstract 322.
Roberts, Thorne and Pearson (1993) describe patients' and nurses' perspectives of dyspnea in late stage cancer. The findings of this study show gaps in nurses' understanding of dyspnea and its management. They contend that the lack of patient education found in their study and in the study by Brown et al (1986) reflects a gap in nurses' skills in providing effective care to these patients, a lack of an accepted standard of care for dyspnea and little evidence of a shared theory base for management strategies. Van den Berg (1995) comments that most of the nursing interventions for dyspnea found in the literature are not research-based. Nursing research is needed on interventions to prevent and treat dyspnea and nurses should always examine their interventions for unwanted consequences such as dyspnea or pain.

\section{Outcomes and evaluations}

Evaluation of outcomes that can be expected for the patient and family include:

- taking measures to minimize the risk of occurrence and severity of dyspneal

- identifying personal risk factors

- reporting to the health care team signs and symptoms of dyspnea

- demonstrating the treatment of severe dyspnea using emergency techniques

- reporting and describing changes in the patient's condition that require professional assistance.

\section{Conclusion}

The person with cancer is at risk of experiencing dyspnea, a distressing experience for both the patient and his/her family. Nursing care is dependent on assessment knowledge and understanding signs and symptoms of respiratory distress. This assessment should identify which management strategies will be more helpful for the patient and his/her family. Nursing interventions must include reassurance and support. Effective teaching should be done before a crisis. Nurses have an important role in helping cancer patients learn techniques to increase their tolerance of dyspnea. Further nursing research is necessary on measuring dyspnea and the interventions to prevent and treat it.

Dudgeon, D.J., Rosenthal, S. (1996). Management of dyspnea and cough in patients with cancer. Hematology/Oncology Clinies of North America, 10(1), 157-171.

Farncombe, M., Chater, S. (1994). Clinical application of nebulized opioids for treatment of dyspnoea in patients with malignant disease. Support Care Cancer, 2(3), 184-187.

Foote, M., Sexton, D.L., Pawlik, L. (1986). Dyspnea: a distressing sensation in lung cancer. Oncology Nursing Forum, 13(5), 25-31.

Gift, A.G. (1990). Dyspnea. Nursing Clinics of North America, 25(4), 955-965.

Grey, A. (1995). Breathless, Nursing Times, 91(27), 46-47.

Haylock, P. (1987). Breathing difficulty: changes in respiratory function. Seminars in Oncology Nursing, 3(4), 293-298.

Held, J. (1994). Managing shortness of breath. Nursing 94, 31.

Roberts, D.K., Thorne, S.E., Pearson, C. (1993). The experience of dyspnea in late-stage cancer. Cancer Nursing, 16(4), 310-320.

Rueben, D.B., Mor, V. (1986). Dyspnea in terminally ill cancer patients. Chest: The Cardiopulmonary Journal, 99(1), 234-236.

Van den Berg, R. (1995). Dyspnea, perception or reality. PCL Review, 2(6). 


\section{Bibliography}

Ajemian, 1. (1991). Palliative management of dyspnea. Journal of Palliative Care, 7(3), 44-45.

Bailey, C. (1995). Nursing as therapy in the management of breathlessness in lung cancer. European Journal of Cancer Care, 4, 184-190.

Brown, M.L., Carrieri, V., Janson-Bjerklie, S., Dodd, M.J. (1986). Lung cancer and dyspnea: the patient's perception. Oncology Nursing Forum, 13(5), 19-24.

Bruera, E., deStoutz, N., Velasco-Leiva, A., Schoeller, T., Hanson, J. (1993). Effects of oxygen on dyspnea in hypoxaemic terminal cancer patients. The Lancet, 342, 13-14.

Bruera, E., Macmillan, K., Pither, J., MacDonald, R.N. (1990). Effects of morphine on the dyspnea of terminal cancer patients. Journal of Pain and Symptom Management, 5(6), 341-344.

Campbell, M. (1996). Managing terminal dyspnea: caring for the patient who refuses intubation or ventilation. Dimensions of Critical Care Nursing, 15(1), 4-11.

Cherniak, N.S., Altose, M.D. (1987). Mechanisms of dyspnea. Clinics in Chest Medicine, 8(2), 207-214.

Clark, J.C., McGee, R.F. (1992). Oncology Nursing Society core curriculum for oncology nursing ( 2 nd ed.). Philadelphia: Saunders.

Cohen, M.H., Johnston-Anderson, A., Krasnow, S.H., Wadleigh, R.G. (1992). Treatment of intractable dyspnea: clinical and ethical issues. Cancer Investigation, 10(4), 317-321.

Corner, J., Plant, H., Bailey, C. (1995). Clearing the air. Nursing Times, 91(47), 42-43.

Cowcher, K., Hanks, G.W. (1990). Long-term management of respiratory symptoms in advanced cancer. Journal of Pain and Symptom Management, 5(5), 320-330.

Dudgeon, D., Kristjanson, L., Khoo, K., Lertzman, M. (1996). Incidence of Dyspnea in Cancer Patients. Proceedings of ASCO (15) Abstract 321.

Dudgeon, D., Lertzman, M. (1996). Etiology of Dyspnea in Advanced Cancer Patients, Proceedings of ASCO, (15), Abstract 322.

Dudgeon, D.J., Rosenthal, S. (1996). Management of dyspnea and cough in patients with cancer. Hematology/Oncology Clinics of North America, 10(1), 157-171.

Enck, R. (1989). Current concepts. The American Journal of Hospice Care, 7, 11-12.

Farncombe, M., Chater, S. (1994). Clinical application of nebulized opioids for treatment of dyspnoea in patients with malignant disease. Support Cancer Care, 2(3), 184-187.

Fishbein, D., Kearon, C., Killian, K.J. (1989). An approach to dyspnea in cancer patients. Journal of Pain and Symptom Management, 4(2), 76-81.

Foote, M., Sexton, D.L., Pawlik, L. (1986). Dyspnea: a distressing sensation in lung cancer. Oncology Nursing Forum, 13(5), 25-31.

Gift, A.G. (1990). Dyspnea. Nursing Clinics of North America, 25(4), 955-965.

Gift, A.G., Pugh, L.C. (1993). Dyspnea and fatigue. Advances in Clinical Nursing Research, 28(2), 373383.

Grey, A. (1995). Breathless. Nursing Times, 91(27), 46-47.

Grey, A. (1995). The nursing management of dyspnea in palliative care. Nursing Times, 91(46), 33-35.

Haylock, P. (1987). Breathing difficulty: changes in respiratory function. Seminars in Oncology Nursing, 3(4), 293 298.

Held, J. (1994). Managing shortness of breath. Nursing 94, 31.

Murciano, D., Auclair, M.H., Pariente, R., Aubier, M. (1989). A randomized controlled trial of theophylline in patients with severe chronic obstructive pulmonary disease. The New England Journal of Medicine, 320(23), 1521-1525.

Roberts, D.K., Thorne, S.E., Pearson, C. (1993). The experience of dyspnea in late-stage cancer. Cancer Nursing 16(4), 310-320.

Rueben, D.B., Mor, V. (1986). Dyspnca in terminally ill cancer patients, Chest: The Cardiopulmonary Journal, 99(1), 234236.

Schwartzstein, R.M., Lahive, K., Pope, A., Weinberger, S.E., Weiss, J.W. (1987). Cold facial stimulation reduces breathlessness induced in normal subjects. American Review of Respiratory Disease, 136, 58-61.

Shepard, K.V. (1989). Dyspnea in cancer patients. PCL Review, 2(6).

Van den Berg, R. (1995). Perception or reality. CACCN, 6(4), 16-19.

Wasserman, K., Casaburi, R. (1989). Dyspnea: physiological and pathophysiological mechanisms. Annual Review of Medicine, 39. 503-515.

Zerwekh, J. (1987). Comforting the dying dyspnea patient. Nursing $87,11,66-69$

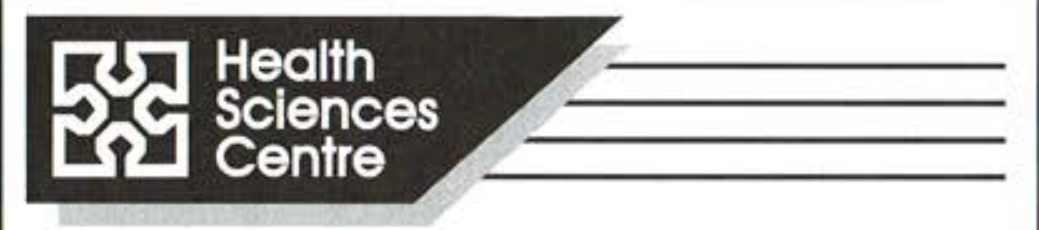

\section{Clinical Nurse Specialist/Nurse Practitioner Pediatric Oncology/Bone Marrow Transplant Program Children's Hospital}

The Health Sciences Centre is an 850 bed tertiary health care facility, affiliated with the University of Manitoba. The Centre is the recognized Trauma and Aboriginal Healthcare Centre for Manitoba, serving a population of over one million.

The Pediatric Program of the Health Sciences Centre is currently seeking to fill the vacant position of Clinical Nurse

Specialist/Nurse Practitioner (permanent/full-time) for the Pediatric Oncology/Bone Marrow Transplant Program. The successful applicant functions in an expanded role which includes Clinical Practitioner, Consultant, Educator and Researcher.

Qualifications include: Master's Degree in Nursing with five years relevant clinical nursing experience, eligibility for registration with the Manitoba Association of Registered Nurses, and a current Basic Life Support certification is required.

Applicants interested in this position should forward a resume to the Nurse Recruiter, Human Resources, Health Sciences Centre, 60 Pearl Street, Winnipeg, Manitoba, R3E 1X2, fax (204) 787-1376. Position is open until filled.

Health Sciences Centre offers a smoke-free environment. 